\title{
Avaliação da confiabilidade de modelos de mobilidade sintéticos aplicados em redes veiculares
}

\author{
Maurício J. Silva ${ }^{1}$, Ricardo A. R. Oliveira ${ }^{1}$, Andre L. L. Aquino ${ }^{2}$ \\ ${ }^{1}$ Departamento de Computação - Universidade Federal de Ouro Preto (UFOP) \\ Rua Diogo Vasconcelos, 122 - Pilar - Ouro Preto - MG - Brasil \\ ${ }^{2}$ Instituto de Computação - Universidade Federal de Alagoas (UFAL) \\ Av. Lourival Melo Mota, s/n - Tabuleiro dos Martins - Maceió - AL - Brazil \\ \{badriciobq, rrabelo\}@gmail.com, alla@laccan.ufal.br
}

\begin{abstract}
Evaluating applications and protocols for vehicular networks is a requirement before employing them in real environments. Generally, this evaluation takes place through simulations because it allows evaluations with low cost and on a large scale. However, for the simulations to produce realistic results, the simulators' mobility models must reproduce the observed behavior in real scenarios. In this work, we developed an epidemic routing algorithm for vehicular networks, and we compared the reliability of the results produced by a mobility model with the results produced in a real scenario. The results show that the mobility model does not reproduce real mobility, and consequently, the applications evaluated in synthetic scenarios do not present the same results when evaluated in real scenarios.
\end{abstract}

Resumo. Avaliar aplicações e protocolos para redes veiculares é um requisito para implantá-los em ambientes reais. Geralmente, essa avaliação acontece por meio de simulações, por permitir que essas avaliações sejam feitas com baixo custo e em larga escala. Porém, para que as simulações produzam resultados realista é necessário que os modelos de mobilidade utilizados pelos simuladores representem fidedignamente o comportamento observado em cenários reais. Neste trabalho, nós apresentamos um algoritmo de roteamento epidêmico para redes veiculares e comparamos a confiabilidade do resultados produzidos por um modelo de mobilidade com os resultados produzidos em um cenário real. Os resultados mostram que o modelo de mobilidade não reproduz a mobilidade real, e consequentemente, as aplicações avaliadas em cenários sintéticos não apresentam os mesmos resultados quando avaliadas em cenários reais.

\section{Introdução}

Diversas aplicações têm surgido com o objetivo de aprimorar os Sistemas de Transporte Inteligentes (ITS), seja com propósitos de melhorar a segurança nas estradas, de reduzir o número de congestionamentos ou de tronar as viagens mais seguras [Fischer 2015, Moura et al. 2018, Macedo et al. 2012]. Avaliar e validar essas aplicações antes de implantá-las em ambientes reais é um requisito importante e que tem ganhado atenção tanto de entidades de pesquisa quanto de órgãos governamentais [Tornell et al. 2015].

É conhecido que o modelo de mobilidade é o principal fator que influencia na avaliação de novos protocolos e aplicações para os Sistemas de Transporte Inteligentes 
(ITS) [Fischer 2015]. Isso, porque veículos possuem características de mobilidade peculiares que têm influência direta nos resultados gerados pela simulação [Harri et al. 2009, Eckhoff and Sommer 2015]. Sendo assim, é fundamental que os modelos de mobilidade representem o mais próximo possível o comportamento veicular observado em cenários reais [Silva et al. 2019].

Neste trabalho, comparamos a avaliação de uma aplicação veicular em um cenário que utiliza dados de mobilidade sintéticos (TAPASCologne) com um cenário que utiliza dados de mobilidade coletados em ambiente real (frota de ônibus). Assim, conseguimos avaliar o impacto que os modelos de mobilidade sintéticos têm durante a avaliação de novas propostas de aplicações e protocolos para redes veiculares. Com isso, mostramos que o comportamento veicular produzido por modelos de mobilidade sintéticos não corresponde ao comportamento veicular observado em cenários reais, o que compromete a avaliação de novas propostas de aplicações para os ITS induzindo pesquisadores a terem conclusões imprecisas.

Foi simulado um algoritmo de roteamento epidêmico para redes tolerantes a atraso em ambos os cenários. Avaliamos o número de mensagens entregues, o tempo de entrega das mensagens, a ocupação dos buffers e o número de saldos das mensagens. Os resultados mostram que o cenário simulado entrega aproximadamente $66 \%$ menos mensagens do o cenário real, porém, com um tempo de entrega aproximadamente cinco vezes menor. Esse resultado nos permite concluir que a conectividade da rede veicular da base sintética é baixa, e consequentemente, mensagens destinadas a nós distantes não alcançam o destino. Adicionalmente, analisamos as velocidades produzidas pelo modelo de mobilidade sintético e identificamos que: (i) elas possuem maior dispersão, em relação as velocidades do cenário real; (ii) possuem altas densidades agrupadas em diferentes níveis de velocidade, $5 \mathrm{~km} / \mathrm{h}, 50 \mathrm{~km} / \mathrm{h}, 75 \mathrm{~km} / \mathrm{h}, 100 \mathrm{~km} / \mathrm{h}$ e $120 \mathrm{~km} / \mathrm{k}$. Enquanto no cenário real observamos um pico de densidade de velocidades aos $40 \mathrm{~km} / \mathrm{h}$, e; (iii) produz velocidades irreais, ou seja, acima de $120 \mathrm{~km} / \mathrm{h}$.

Este artigo está organizado da seguinte forma. Na seção 2, apresentamos as características dos modelos de mobilidade para redes veiculares e detalhamos o modelo de Krauss. Na seção 3, descrevemos as bases de dados utilizadas e os cenários de avaliação. Na seção 4, avaliamos e discutimos os resultados obtidos. Por fim, na seção 5, apresentamos as conclusões deste trabalho e as direções de trabalhos futuros.

\section{Modelos de mobilidade veicular}

O modelo de mobilidade é o principal fator que influencia na avaliação de novos protocolos e aplicações para os ITS [Fischer 2015]. Isso, porque veículos possuem características de mobilidade peculiares que têm influência direta nos resultados gerados pela simulação [Harri et al. 2009, Eckhoff and Sommer 2015]. É desejável que as simulações produzam resultados mais próximos possíveis dos resultados observados em cenários reais, o que exige que os modelos de mobilidade sejam validados antes de serem utilizados.

Vários modelos de mobilidade veicular surgiram com o passar dos anos, e esses modelos evoluíram desde modelos puramente aleatórios até modelos baseados em comportamento [Silva et al. 2018, Sommer and Dressler 2008]. A maioria desses modelos já estão implementados nos principais simuladores de mobilidade veicular, e são utilizados pela comunidade científica para conduzir seus experimentos. 
Uma das principais desvantagens em simulações de redes veiculares encontra-se em sua acurácia. Ou seja, na capacidade dessas simulações reproduzirem de forma realista a dinâmica de tráfego presente em cenários reais. Para isso, os simuladores de redes veiculares levam em consideração dois diferentes escopos dentro de um cenário, a macro-mobilidade e a micro-mobilidade. A macro-mobilidade leva em conta a topologia da rede e sua estrutura, como por exemplo o número de pistas de uma rodovia e o sentido do tráfego. Outros fatores relevantes no macro cenário estão relacionados com as características do tráfego (limites de velocidade para cada categoria de veículo), a presença de restrições de tráfego (regras de trânsito e semáforos) e os efeitos causados por pontos de interesse (centros comerciais, escolas, hospitais, etc).

A micro-mobilidade diz respeito ao comportamento de cada veículo individualmente. Para isso, assume-se que o comportamento do veículo pode estar relacionado com dois fatores, a capacidade física do veículo de se mover, e com o comportamento do motorista. Os principais parâmetros que devem ser fornecidos para modelos de micromobilidade são: velocidade máxima permitida em cada via para diferentes classes de veículos, critérios de aceleração e desaceleração, regras de tráfego na presença de cruzamentos e semáforos, e um fator de imperfeição que tem como objetivo modelar o comportamento do motorista, geralmente relacionado com idade, sexo, maturidade, etc.

O principal modelo de micro-mobilidade utilizado pela comunidade acadêmica é o modelo de Krauss [Krauß 1998]. Isso, porque a comunidade acadêmica considera que o modelo de Krauss reproduz a mobilidade veicular com um grau de realismo satisfatório. Característica que faz com que ele seja implementado nos principais simuladores de tráfego veicular e utilizado pela comunidade científica para conduzir suas simulações.

\subsection{Modelo de Krauss}

Krauss et al. [Krauß et al. 1996, Krauß 1998, Krauß et al. 1997] propôs um modelo estocástico, continuo no espaço e discreto no tempo, que é capaz de descrever as principais características do tráfego veicular, como por exemplo tráfego livre ou congestionamentos. O modelo de Krauss leva em consideração quatro variáveis de entrada, que são: a velocidade máxima $v_{\max }$, a aceleração máxima $a(v)$, a desaceleração máxima $b(v)$ e um ruído que introduz comportamento estocástico ao modelo [Behrisch et al. 2010].

Para relacionar a velocidade com as propriedades físicas do veículo, a velocidade desejada é computada como o menor valor entre: a velocidade máxima que o veículo pode atingir, a velocidade atual do veículo mais a aceleração máxima e a velocidade de segurança. Assim, a velocidade desejada é calculada por

$$
v_{\text {des }}=\min \left[v_{\max }, v+a(v), v_{\text {safe }}\right],
$$

onde, $v_{\max }$ é a velocidade máxima que um veículo pode atingir, $v+a(v)$ é a velocidade do veículo somado a aceleração do veículo (baseado na categoria do veículo) e $v_{s a f e}$ é a velocidade de segurança. Dessa forma, o veículo não irá acelerar ou ultrapassar a velocidade limite.

Adicionalmente, o modelo de Krauss modela os erros cometidos pelos motoristas adicionando um valor randômico uniformemente distribuído entre um intervalo fixo definido de acordo com

$$
v=\max \left[0, \operatorname{rand}\left(v_{d e s}-a, v_{d e s}\right)\right]
$$


onde, $a$ é a aceleração do veículo e $v_{\text {des }}$ é a velocidade desejada que o veículo atinja. A velocidade desejada de um veículo tende a atingir a velocidade máxima da pista, este comportamento têm influência direta na dinâmica de tráfego gerada pelos simuladores.

Em cada intervalo de tempo, a velocidade do veículo é adaptada a velocidade do veículo da frente com o objetivo de garantir que o modelo seja livre de colisões. Essa velocidade é chamada velocidade de segurança $v_{s a f e}$, calculada por

$$
v_{\text {safe }}(t)=v_{l}(t)+\frac{g(t)-v_{l}(t) \tau}{\frac{\hat{v}}{b(\hat{v})}+\tau},
$$

onde, $v_{l}(t)$ é a velocidade do veículo predecessor no tempo $t, g(t)$ é o gap (distância do veículo da frente) no tempo (t), $\tau$ é o tempo de reação do motorista (geralmente $1 \mathrm{~s}$ ) e $b(\hat{v})$ é a função de desaceleração do veículo.

A importância do modelo de Krauss encontra-se no fato de que ele identificou que existem diferentes regimes de tráfego dependendo dos parâmetros do modelo. Ou seja, variando os valores de $a(v)$ e $b(v)$ é possível identificar três diferentes classes de tráfego [Chowdhury et al. 2000, Nagel et al. 2003]: i) Para valores altos de $a(v)$ e $b(v)$ o modelo não apresenta formação de estruturas, ou seja, o distribuição espaço-temporal parece homogênea. ii) Diminuindo o valor de $a(v)$ mas mantendo grandes valores para $b(v)$, é introduzido um regime onde a distribuição espaço-temporal apresenta padrões complicados de pequenos congestionamentos dentro de grandes congestionamentos. iii) Quando valores moderados para $a(v)$ e $b(v)$ são alcançados, e a densidade é grande o suficiente por longos períodos de tempo, a distribuição espaço temporal apresenta grandes congestionamentos que crescem enquanto o número de pequenos congestionamentos diminui.

\section{Metodologia}

Avaliar a confiabilidade dos dados produzidos por modelos de mobilidade é essencial para entendermos como esses modelos afetam os resultados produzidos por simulações. Com a finalidade de avaliarmos a confiabilidade do modelo de Krauss em relação a cenários reais, comparamos uma base de dados sintéticos realista com uma base de dados reais. A seguir, detalhamos as bases de dados e a metodologia utiliza para conduzir a avaliação.

\subsection{Bases de dados utilizadas}

Neste trabalho, utilizamos duas bases de dados, uma com dados reais e outra com dados sintéticos, para avaliarmos o desempenho de uma aplicação projetada para redes veiculares. A base de dados reais compreende em dados coletados de uma frota de ônibus pela empresa SEVA ${ }^{1}$, que é uma empresa de tacógrafos da cidade de Belo Horizonte. Nessa base, os registros de velocidade são associados com um par de coordenadas correspondente ao lugar no qual o registro foi coletado. Ela possui informações coletadas a partir de tacógrafos instalados em 12 ônibus urbanos da cidade de Belo Horizonte entre os dias $12 / 12 / 2012$ e 18/02/13. A região de interesse desta base de dados possui dimensões de $32,17 \mathrm{~km}$ por $15,50 \mathrm{~km}$ e é formada por avenidas e vias secundárias de um grande centro urbano. Para cada ônibus foi coletado uma arquivo de $\log$ por dia. Cada arquivo de log

\footnotetext{
${ }^{1}$ http://projetoseva.com.br/
} 
possui um registro por linha que foram coletados em intervalos de 1s, somando um total de 1.746 .875 registros. O primeiro e o segundo campos presentes no arquivo correspondem a longitude e latitude respectivamente, o terceiro campo é a velocidade do veículo em $\mathrm{km} / \mathrm{h}$ e o quarto e último campo é o horário do dia em que o registro foi feito, o qual está no formato de HH:MM:SS.

Para os dados sintéticos, utilizamos uma base de dados chamada TAPASCologne produzida por Uppoor et al. [Uppoor et al. 2014] utilizando o simulador de micro tráfego SUMO [Krajzewicz et al. 2002]. Para isso, eles extraíram os layouts das ruas de uma área de aproximadamente $400 \mathrm{~km}^{2}$ da cidade de Cologne, na Alemanha, utilizando o OpenStreetMap (OSM) ${ }^{2}$. Em seguida utilizaram o Java OSM (JOSM) ${ }^{3}$ para corrigir manualmente, por inspeção visual, as informações erradas exportadas pelo OSM tornando-o compatível com o SUMO. Os autores corrigiram aproximadamente 200 mil informações inconsistentes, tais como ruas que estavam incompletas ou restrições de conversão em cruzamentos.

Para gerar demanda de tráfego, os autores utilizaram informações de viagens de motoristas e padrões de atividades coletadas a partir de dados reais. Com isso, eles geraram um matriz de origem/destino (O/D) explorando informações de 1.2 milhões de viagens individuais de 700 moradores da cidade de Cologne por um período de um dia (24 horas). Embora os autores tenham feito todas as correções no mapa e na matriz de O/D, eles observaram comportamento de tráfego irrealista gerado pelo algoritmo de Dijkstra que é utilizado pelo SUMO para calcular a menor rota entre origem e destino. Para resolver esse problema, eles alteraram o SUMO para utilizar o algoritmo de Gawron [Gawron 1998], que calcula o caminho entre a origem e o destino de forma dinâmica, considerando as condições do trânsito.

Com isso, a base de dados TAPASCologne compreende em 700 mil viagens de carros na área metropolitana da cidade de Cologne em um período de 24 horas. A base de dados TAPASCologne está publicamente disponível como um arquivo de trace em um formato genérico. Ou seja, cada linha do arquivo de trace contém informações de tempo (em intervalos de $1 s$ ), do identificador do veículo, da posição do veículo em um plano bidimensional e a velocidade do veículo em metros por segundo. A comunidade acadêmica considera a base de dados TAPASColone como uma das mais realistas disponível publicamente para uso [Naboulsi and Fiore 2017, Wang et al. 2018, Kong et al. 2018, Rahim et al. 2018].

\subsection{Algoritmo avaliado com as bases}

Para a avaliação, foi desenvolvido um algoritmo de roteamento epidêmico para redes veiculares utilizando o simulador de redes OMNeT++ [Varga 2010]. O algoritmo é capaz de entregar mensagens em uma rede tolerante a atraso. Isso significa que cada veículo possui um buffer onde armazena a mensagem e aguarda por uma oportunidade de contato para transmiti-la ao veículo seguinte. Esse processo se repete até que a mensagem alcance seu destino.

A Figura 1 ilustra o funcionamento do algoritmo de roteamento epidêmico: (i) quando o nó $A$ entra na área de contato do nó $B$, o no $B$ envia para $A$ uma mensagens

\footnotetext{
${ }^{2} \mathrm{https}: / /$ www.openstreetmap.org/

${ }^{3} \mathrm{http}: / /$ josm.openstreetmap.de/
} 
de sincronização com informações das mensagens de dados que $B$ tem sob custódia; (ii) quando o nó $A$ recebe a mensagem de sincronização, ele verifica quais mensagens ele não possui em buffer e envia ao nó $B$ uma solicitação de custódia para estas mensagens; (iii) ao receber a solicitação de custódia, o nó $B$ envia as mensagens de dados para o nó $A$. Esse processo acontece nos dois sentidos de forma que, ao final do processo, ambos os nós estejam com as mesmas mensagens em buffer e sejam capazes de transportá-las pela rede pulverizando-as para os demais nós que encontrarem pelo caminho.

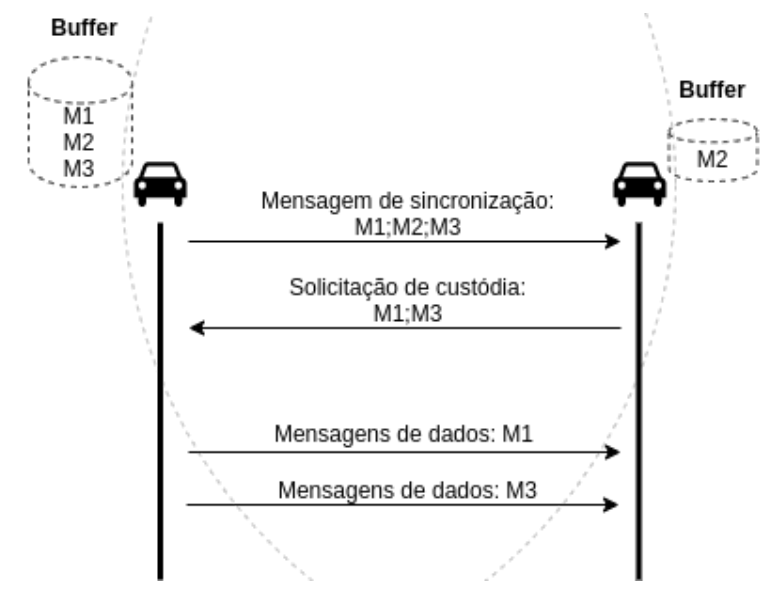

Figura 1. Funcionamento do algoritmo epidêmico

Para os experimentos foram utilizados dois cenários, o primeiro, com uma base de dados reais e segundo com uma base de dados sintéticos considerada realista. Para o primeiro cenário, foi utilizada a base de dados de ônibus, que é composta por 12 ônibus que circulam por uma área de $32 \mathrm{~km}$ por $15 \mathrm{~km}$ durante as 24 horas de um dia. Para o segundo cenário foi utilizada a base de dados TAPASCologne, onde foram selecionados 30 veículos aleatórios para cada uma das 15 repetições. Nessa base de dados os veículos circulam por uma área de $30 \mathrm{~km}$ quadrados durante as 24 horas de um dia. Para ambas as bases foram executadas 15 repetições onde em cada repetição os destinos e as origens das mensagens eram gerada de forma aleatória respeitando a condição de que o destino tinha que ser diferente da origem.

A base de dados TAPASCologne representa a mobilidade veicular de uma cidade durante as 24 horas do dia, porém, os veículos nessa base entram na simulação no início do trajeto e saem da simulação no final do trajeto permanecendo na simulação por poucos minutos. Por esse motivo, ao selecionarmos 30 veículos aleatórios o tempo de simulação, em que os veículos estão em movimento, ficou próximo a 1400 segundos, este tempo foi utilizando para executar as simulações para ambas as bases. Para a base de dados de ônibus, a simulação inicia após a rede iniciar e os nós se espalharem pela área de simulação, isso, porque os dados da base foram coletados com os veículos ainda na garagem.

\section{Resultados}

Como mencionado anteriormente, para que novas aplicações e protocolos para redes veiculares sejam avaliados adequadamente, é essencial que as bases de dados sintéticas produzam comportamento veicular semelhante ao comportamento observado em cenários 
reais. Com o objetivo de confirmar a fidelidade de uma base sintética considerada pela comunidade científica como realista, nós avaliamos o desempenho do algoritmo epidêmico para redes veiculares e comparamos os resultados produzidos no cenário real, com os resultados produzidos no cenário cenário sintético.

Ambos os cenário são avaliados em relação ao número de mensagens entregues, ao tempo de entrega de mensagem, a ocupação dos buffers de cada nó e ao número de saltos de cada mensagem. O número de mensagens entregues permite avaliar a confiabilidade dos modelos de mobilidade implementados, ou seja, se ambos os modelos geram mobilidade cujas oportunidades de contato são exploradas adequadamente pelos protocolos avaliados. O tempo de entrega de mensagem e o número de saltos de cada mensagem estão intimamente relacionados com o parâmetro anterior e avalia se as oportunidades de contato podem ser exploradas pelos protocolos de forma eficiente. Por fim, a ocupação do buffer de cada nó permite avaliar o espaço de armazenamento de cada nó e a eficiência dos protocolos ao propagar as mensagens pela rede. Observe que, como mencionado anteriormente, o modelo de mobilidade está intimamente ligado ao desempenho das aplicações e protocolos projetados para redes veiculares. Sendo assim, deseja-se que ambos os cenários apresentem comportamentos semelhantes.

Tabela 1. Base de dados de ônibus x TAPASCologne: Dados estatísticos

\begin{tabular}{lcccccc}
\hline \multirow{2}{*}{ Parâmetros } & \multicolumn{3}{c}{ Ônibus } & \multicolumn{3}{c}{ TAPASCologne } \\
\cline { 2 - 7 } & Total & Média & Desv. Padão & Total & Média & Desv. Padão \\
\hline Tempo de entrega & 10813,6 & 2163,0 & 535,4 & 832,9 & 416,5 & 17,8 \\
Mensagens entregues & 6 & 0,4 & 0,63 & 2 & 0,133 & 5,93 \\
Ocupação dos buffers (\# de mensagens) & 74 & 4,93 & 2,86 & 63 & 4,2 & 3,58 \\
\# de saltos & 75 & 5,0 & 3,64 & 72 & 4,8 & 5,93 \\
\hline
\end{tabular}

A Tabela 1 apresenta os resultados para os parâmetros analisados. O número de mensagens entregues na base de dados de ônibus é relativamente maior do que a base de dados TAPASCologne, isso nos permite concluir que a base de dados de ônibus é mais conexa, e que a mobilidade dos veículos é melhor explorada para garantir que a mensagem alcance o destino. Outro parâmetro que confirma essa hipótese é o tempo médio de entrega de mensagens. $\mathrm{O}$ fato do tempo médio de entrega de mensagens na base TAPASCologne ser pequeno, e possuir uma pequena variação, indica que as mensagens foram geradas e entregues para nós próximos ao destino, o que nos permite concluir que a conectividade da rede nessa base de dados é baixa e consequentemente, mensagens destinadas a nós distantes dificilmente alcançam seus destinos. Além disso, a relação entre o número de saltos e a ocupação dos buffers indica que na base TAPASCologne as mensagens são mais propagadas pela rede passando por um número maior de nós intermediários antes de alcançar o destino.

Aprofundando as análises, com o objetivo de identificarmos diferenças no comportamento veicular produzido pelo modelo de mobilidade em relação ao comportamento veicular real, analisamos os dados das velocidade de ambos cenários. Isso, porque a velocidade é uma importante variável para identificarmos a fidelidade dos modelos de mobilidade em relação aos cenários reais. A Figura 2 apresenta o violin plot juntamente com o boxplot para os dados de velocidade de ambos os cenários. Através do violin plot conseguimos identificar a densidade e a distribuição das velocidades, informações que são 


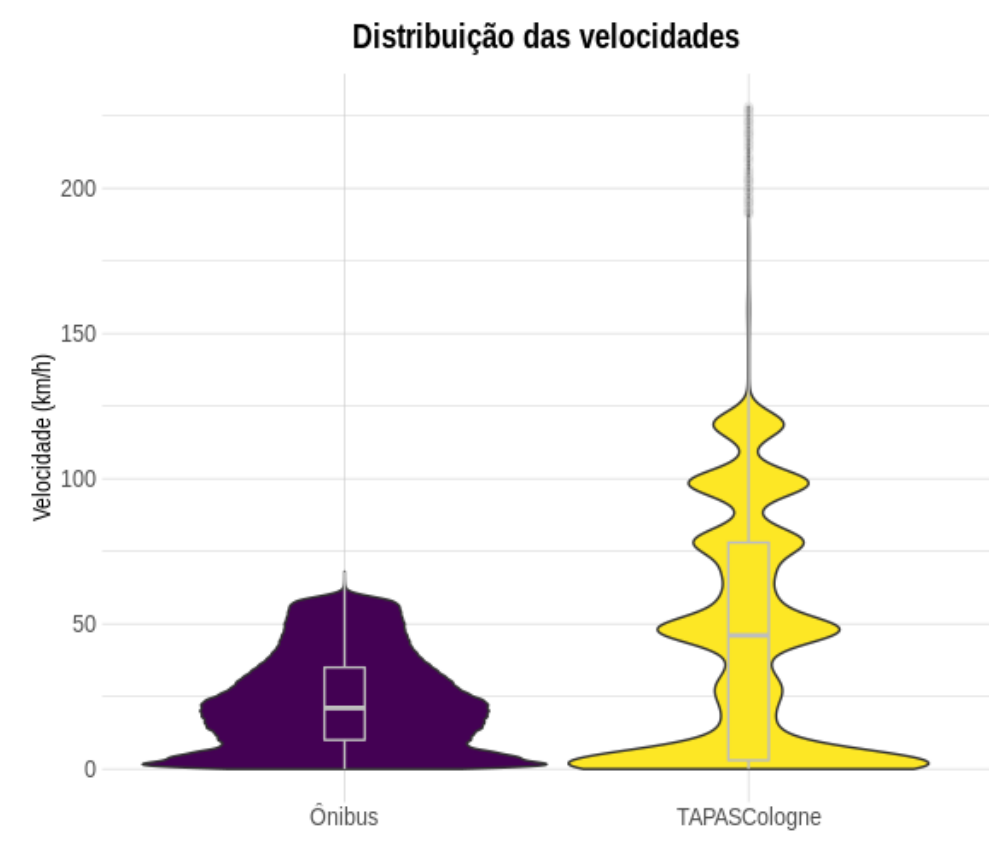

Figura 2. Violin e boxplot das velocidades veiculares

omitidas pelo boxplot. Ao observarmos a Figura 2 notamos que as velocidades produzidas pelo modelo sintético possuem maior dispersão, em relação as velocidades do cenário real. Além disso, notamos que as velocidades formam grupos com altas densidades e picos em $5 \mathrm{~km} / \mathrm{h}, 50 \mathrm{~km} / \mathrm{h}, 75 \mathrm{~km} / \mathrm{h}, 100 \mathrm{~km} / \mathrm{h}$ e $120 \mathrm{~km} / \mathrm{k}$. Enquanto no cenário real nos observamos um pico de densidade de velocidades aos $40 \mathrm{~km} / \mathrm{h}$. A base TAPASCologne é composta por diversas categorias de veículos o que pode justificar uma maior dispersão das velocidades se comparada com o cenário real (frota de ônibus). Além disso, os ônibus possuem uma rota menos dinâmica (com paradas) se comparada as rotas de veículos de outras categorias, o que pode justificar uma maior taxa de entrega das mensagens. Outra observação importante diz respeito aos outliers observados no boxplot da base TAPASCologne, onde conseguimos notar que a base TAPASCologne possui velocidades superiores a $200 \mathrm{~km} / \mathrm{h}$, o que não corresponde a realidade.

Estes resultados mostram que a dinâmica de tráfego gerada por simuladores não representam o comportamento de cenários reais. Adicionalmente, nossa hipótese é que não é possível distinguir diferentes categorias de veículos dentro do cenário simulado. Ou seja, a dinâmica de tráfego produzida pelos simuladores não nos permite selecionar veículos que possuem o mesmo comportamento observado em cenários reais, em diferentes condições de tráfego e para diferentes categorias de veículos.

\section{Conclusões}

Avaliar aplicações e protocolos para redes veiculares é um requisito para implantá-los em ambiente real. Geralmente, essa avaliação acontece por meio de simulações, por permitir que essas avaliações sejam feitas com baixo custo e em larga escala. Porém, para que as simulações produzam resultados realista é necessário que os modelos de mobilidade utilizados pelos simulares representam o comportamento observado em cenários reais.

Neste trabalho, foi simulado um algoritmo de roteamento epidêmico para redes 
tolerantes a atraso em ambos os cenários. Avaliamos o número de mensagens entregues, o tempo de entrega das mensagens, a ocupação dos buffers e o número de saldos das mensagens. Os resultados mostram que o cenário simulado entrega aproximadamente $66 \%$ menos mensagens do no cenário real, porém, com um tempo de entrega aproximadamente cinco vezes menor. Esse resultado nos permite concluir que a conectividade da rede veicular da base sintética é baixa, e consequentemente, mensagens destinadas a nós distantes não alcançam o destino. Adicionalmente, analisamos as velocidades produzidas pelo modelo de mobilidade sintético e identificamos que: (i) elas possuem maior dispersão, em relação as velocidades do cenário real; (ii) possuem altas densidades agrupadas em diferentes níveis de velocidade, $5 \mathrm{~km} / \mathrm{h}, 50 \mathrm{~km} / \mathrm{h}, 75 \mathrm{~km} / \mathrm{h}, 100 \mathrm{~km} / \mathrm{h}$ e $120 \mathrm{~km} / \mathrm{k}$. Enquanto no cenário real nos observamos um pico de densidade de velocidades aos $40 \mathrm{~km} / \mathrm{h}$, e; (iii) produz velocidades irreais, ou seja, acima de $120 \mathrm{~km} / \mathrm{h}$.

Estes resultados nos permitem concluir que a dinâmica de tráfego gerada por simuladores não representam o comportamento observado em cenários reais. Adicionalmente, nossa hipótese é que não é possível distinguir diferentes categorias de veículos dentro do cenário simulado. Ou seja, a dinâmica de tráfego produzida pelos simuladores não nos permite selecionar veículos que possuem o mesmo comportamento observado em cenários reais, em diferentes condições de tráfego e para diferentes categorias de veículos.

\section{Agradecimentos}

O presente trabalho foi realizado com apoio da Coordenação de Aperfeiçoamento de Pessoal de Nível Superior - Brasil (CAPES) - Código de Financiamento 001, do Conselho Nacional de Desenvolvimento Científico e Tecnológico (CNPQ), da Fundação de Amparo à Pesquisa do Estado de Minas Gerais (FAPEMIG), da Universidade Federal de Ouro Preto (UFOP), e da Universidade Federal de Alagoas (UFAL). Os autores também gostariam de agradecer a empresa Sascar por fornecer os dados utilizados nesta pesquisa.

\section{Referências}

Behrisch, M., Erdmann, J., and Krajzewicz, D. (2010). Adding intermodality to the microscopic simulation package sumo. MESM, pages 59-66.

Chowdhury, D., Santen, L., and Schadschneider, A. (2000). Statistical physics of vehicular traffic and some related systems. Physics Reports, 329(4-6):199-329.

Eckhoff, D. and Sommer, C. (2015). Simulative performance evaluation of vehicular networks. Vehicular Communications and Networks: Architectures, Protocols, Operation and Deployment, pages 255-274.

Fischer, H.-J. (2015). Standardization and Harmonization Activities Towards a Global C-ITS, pages 23-36. Springer International Publishing.

Gawron, C. (1998). An iterative algorithm to determine the dynamic user equilibrium in a traffic simulation model. International Journal of Modern Physics C, 9(03):393-407.

Harri, J., Filali, F., and Bonnet, C. (2009). Mobility models for vehicular ad hoc networks: a survey and taxonomy. IEEE Communications Surveys Tutorials, 11(4):19-41.

Kong, X., Xia, F., Ning, Z., Rahim, A., Cai, Y., Gao, Z., and Ma, J. (2018). Mobility dataset generation for vehicular social networks based on floating car data. IEEE Transactions on Vehicular Technology, 67(5):3874-3886. 
Krajzewicz, D., Hertkorn, G., Rössel, C., and Wagner, P. (2002). Sumo (simulation of urban mobility)-an open-source traffic simulation. In Proceedings of the 4th Middle East Symposium on Simulation and Modelling.

Krauß, S. (1998). Microscopic modeling of traffic flow: Investigation of collision free vehicle dynamics. PhD thesis, Dt. Zentrum für Luft-und Raumfahrt eV, Abt. Unternehmensorganisation und ....

Krauß, S., Wagner, P., and Gawron, C. (1996). Continuous limit of the nagelschreckenberg model. Physical Review E, 54(4):3707.

Krauß, S., Wagner, P., and Gawron, C. (1997). Metastable states in a microscopic model of traffic flow. Physical Review E, 55(5):5597.

Macedo, D. F., Oliveira, S., Teixeira, F. A., Aquino, A. L. L., and Oliveira, R. R. (2012). $(\mathrm{CIA})^{2}$-ITS: Interconnecting mobile and ubiquitous devices for intelligent transportation systems. In IEEE Pervasive Computing and Communication.

Moura, D. L. L., Cabral, R. S., Sales, T., and Aquino, A. L. L. (2018). An evolutionary algorithm for roadside unit deployment with betweenness centrality preprocessing. $\mathrm{Fu}$ ture Generation Computer Systems, 88(1):776-784.

Naboulsi, D. and Fiore, M. (2017). Characterizing the instantaneous connectivity of large-scale urban vehicular networks. IEEE Transactions on Mobile Computing, 16(5):1272-1286.

Nagel, K., Wagner, P., and Woesler, R. (2003). Still flowing: Approaches to traffic flow and traffic jam modeling. Operations research, 51(5):681-710.

Rahim, A., Kong, X., Xia, F., Ning, Z., Ullah, N., Wang, J., and Das, S. K. (2018). Vehicular social networks: A survey. Pervasive and Mobile Computing, 43:96 - 113.

Silva, M. J., Cavalcante, T. S., Rosso, O. A., Rodrigues, J. J., Oliveira, R. A., and Aquino, A. L. (2019). Study about vehicles velocities using time causal information theory quantifiers. Ad Hoc Networks, 89:22 - 34.

Silva, M. J., Silva, G. I., Teixeira, F. A., and Oliveira, R. A. (2018). Temporal evolution of vehicular network simulators: Challenges and perspectives. In Proceedings of the 20th International Conference on Enterprise Information Systems.

Sommer, C. and Dressler, F. (2008). Progressing toward realistic mobility models in vanet simulations. IEEE Communications Magazine, 46(11):132-137.

Tornell, S. M., Calafate, C. T., Cano, J. C., and Manzoni, P. (2015). Dtn protocols for vehicular networks: An application oriented overview. IEEE Communications Surveys Tutorials, 17:868-887.

Uppoor, S., Trullols-Cruces, O., Fiore, M., and Barcelo-Ordinas, J. M. (2014). Generation and analysis of a large-scale urban vehicular mobility dataset. IEEE Transactions on Mobile Computing, 13(5):1061-1075.

Varga, A. (2010). OMNeT++, pages 35-59. Springer Berlin Heidelberg.

Wang, J., Jiang, C., Zhang, K., Quek, T. Q. S., Ren, Y., and Hanzo, L. (2018). Vehicular sensing networks in a smart city: Principles, technologies and applications. IEEE Wireless Communications, 25(1):122-132. 